\title{
ENTRE A AUTONOMIA E A HETERONOMIA DA VONTADE NAS RELAÇÕES CONTRATUAIS
}

\author{
BETWEEN AUTONOMY AND WILL HETERONOMY IN \\ CONTRACTUAL RELATIONS
}

\author{
Roberto Correia da Silva Gomes Caldas ${ }^{1}$ \\ Hélcio Kronberg ${ }^{2}$ \\ Gustavo Afonso Martins ${ }^{3}$
}

\begin{abstract}
RESUMO
O presente artigo analisa o instituto da autonomia da vontade como referencial para o negócio jurídico. Isso se dá, na perspectiva da pesquisa, quanto àquilo quanto possível para aproximar o Direito do Trabalho e o Direito Civil no que tange a matéria de contratos que é posterior à autonomia da vontade de contratar.
\end{abstract}

PALAVRAS-CHAVE: Relações Contratuais; Negócio Jurídico; Autonomia da vontade.

\begin{abstract}
This paper analyzes the institute of autonomy of will as a reference for the legal business. From the perspective of the research, this is as far as possible to bring labor and civil law closer together with regard to the subject of contracts that is subsequent to the autonomy of the will to contract.
\end{abstract}

KEYWORDS: Contractual Relations; Juridic business; Autonomy of will.

\section{INTRODUÇÃO}

\footnotetext{
1 Possui Doutorado em Direito Administrativo pela Pontifícia Universidade Católica de São Paulo (2008), Mestrado em Direito Tributário pela Pontifícia Universidade Católica de São Paulo (2002) e Bacharelado em Direito pela Pontifícia Universidade Católica de São Paulo (1993). Professor permanente dos Cursos de Mestrado e Bacharelado em Direito do Centro Universitário das Faculdades Metropolitanas Unidas - FMU. Professor permanente dos Cursos de Mestrado e Bacharelado em Direito da UNINOVE

- Universidade Nove de Julho (2014-2019).

2 Investigador, membro dos grupos de pesquisa Cidadania Empresarial no Século XXI UNICURITIBA - Brasil, e integrante do grupo de Pesquisa Internacional - REDTH (Rede de Estudos em Direitos Humanos e Transnacionalidade).

3 Doutorando em Direito Empresarial e Cidadania pelo Centro Universitário Curitiba UNICURITIBA. Mestre em Direito Empresarial e Cidadania pelo Centro Universitário Curitiba UNICURITIBA. Curso em Direito Internacional Público e Direitos Humanos - organizado pelo lus Gentium Conimbrigae - Centro de Direitos Humanos. Universidade de Coimbra-Pt. Advogado desde 2012. Área: Direito Civil, Direito do Trabalho e Direito Empresarial. Escritório de Advocacia particular. Professor de Direito Empresarial na Faculdade Pinhais - FAPI.
} 
A abordagem sobre a autonomia da vontade exige uma prévia explicação de sua delimitação, qual seja, aquela que diz respeito aos contratos de natureza trabalhista e civilista. Nesseparticular, a autonomia da vontade se manifesta/apresenta em um contrato o qual, por sua vez é uma modalidade de negócio jurídico com tutela no ordenamento jurídico brasileiro, civil e trabalhista por exemplo. Por fim, o objetivo é traçar um paralelo entre a autonomia da vontade pelo viés jurídico, sua classificação e conceituação, tangenciar pela perspectiva filosófica para buscar subsidio a fim de distinguir autonomia de heteronomia da vontade e, por fim, abordar a temática pela premissa pragmática. Em outras palavras, se a autonomia da vontade (privada individual ou coletiva) não é plena, pode valer-se de uma conotação filosófica para afastar o negócio jurídico pactuado às margens da autonomia da vontade plena?

Ainda, o trabalho visa analisar se as hipóteses de nulidade ${ }^{4}$ e/ou anulação ${ }^{5}$ do negócio jurídico já seriam modalidade em que se verifica a presença da heteronomia da vontade em detrimento à autonomia. Diante dessa abordagem jurídica e filosófica, partir-se-á para o viés pragmático da aplicação da norma.

\section{CARACTERÍSTICAS DO CONTRATO DE DIREITO CIVIL E SUA SIMILITUDE COM O CONTRATO LABORAL}

Importa tratar dos contratos bilaterais ou sinalagmáticos os quais são, via de regra, a classificação dos contratos de trabalho, vez que geram obrigações ambas as partes. (CASSETTARI, 2013, p. 184).

Isso também se liga aos contratos de natureza laboral vez que disciplina a relação contratual entre partes desiguais economicamente, pelo menos em sua

\footnotetext{
${ }^{4}$ Art. 171. Além dos casos expressamente declarados na lei, é anulável o negócio jurídico: I - por incapacidade relativa do agente; II - por vício resultante de erro, dolo, coação, estado de perigo, lesão ou fraude contra credores.

${ }^{5}$ Art. 166. É nulo o negócio jurídico quando: I - celebrado por pessoa absolutamente incapaz; II - for ilícito, impossível ou indeterminável o seu objeto; III - o motivo determinante, comum a ambas as partes, for ilícito; IV - não revestir a forma prescrita em lei;
} 
maioria. Portanto, a posição de inferioridade técnica e/ou econômica tanto na relação de consumo como na relação de trabalho se assemelham na medida que se está diante de uma dicotomia de posições e condições de negociar e estabelecer cláusulas contratuais.

De qualquer sorte, importante destacar a aproximação principiológica entre ambos os códigos se dá em função do Código Civil incorporar dois princípios contratuais sociais: função social do contrato e boa-fé objetiva. (CASSETARI, 2013,

p. 182). Veja-se que os princípios acima dialogam com a relação contratual empregatícia além daqueles próprios do direito do trabalho.

O Código Civil de 2002 (BRASIL, 2002) apresenta as disposições gerais no que tange os contatos a partir do artigo 421, versa que "a liberdade de contratar será exercida em razão e nos limites da função social do contrato". Este é um dos princípios que norteiam as relações contratuais, contudo, é oportuno destacar que com o advento da Constituição de 1988 (BRASIL, 1988) o Direito Civil (BRASIL, 2002) passa a ser constitucionalizado e os princípios da Carta Magna, por exemplo, da dignidade da pessoa humana (art. 1, III, CF/88), da solidariedade social (art. 3, I, da CF/88) e da isonomia (art. 5 da CF/88) também se aplicam ao Direito Civil, e, consequentemente, ao contrato. (BRASIL, 1998).

Portanto, nas palavras de Cassettari (2013, p. 188) "os princípios que norteiam a relação contratual são: autonomia privada; função social do contrato; boa- fé objetiva; força obrigatória; e relatividade dos efeitos do contrato".

Essa é a conceituação e base principiológica dos contratos de natureza civil, por outro, para atingir a correlação e aproximação existente, vale-se, por oportuno, da classificação de Maranhão (1997, p. 247/247) que entende:

Ser um contrato de trabalho a) Um contrato de direito privado. (...); b) um contrato concluído intuitu personae em relação à pessoa do empregado. É uma consequência lógica do caráter fiduciário, que the é próprio. (...);c) um contrato silanagmático: dele resultam obrigações contrárias e equivalentes;

d) um contrato consensual. A lei, via de regra, não exige forma especial para sua validade: solus consensus obligat; e) um contrato sucessivo, a relação

jurídica do trabalho é "uma relação de débito permanente", em que entra, como elemento típico, a continuidade, a duração; f) um contrato oneroso: à prestação de trabalho corresponde a contraprestação de salário. 
A Consolidação das Leis do Trabalho - CLT - dispõe em seu artigo 443 que "o contrato individual de trabalho poderá ser acordado tácita ou expressamente, verbalmente ou por escrito, por prazo determinado ou indeterminado, ou para prestação de trabalho intermitente". (BRASIL, 2017a).

O contrato de trabalho, assim como outro negócio jurídico, para a sua validade depende do preenchimento de alguns requisitos disciplinados no Código Civil de 2002 no artigo 104 que dispõe: "a validade do negócio jurídico requer: I - agente capaz; II-objeto lícito, possível, determinado ou determinável; III - forma prescrita ou não defesa em lei". (BRASIL, 2002).

Assim, dada a importância social do fato da prestação de trabalho subordinado, embora a constituição da relação jurídica dependa, também aqui, de um contrato, sua disciplina decorre, cada vez mais, de fontes estranhas à vontade dos contratantes (MARANHÃO, 1997, p. 237). Isso significa a vinculação do direito do trabalho com a Constituição Federal e demais diplomas legais protetivos às partes vulneráveis nas relações que lá são disciplinadas.

Conforme seguirá, a intervenção indireta do Estado por intermédio da legislação com a redação contida no $\S^{\circ}$ o art. $8^{\circ}$ da Lei 13.467/17 (BRASIL, 2017a) que orienta a justiça do trabalho a analisar exclusivamente a conformidade dos elementos essenciais do negócio jurídico, respeitado o disposto no art. 104 da Lei ㄲo. 10.406/2002 (BRASIL, 2002) e balizará sua atuação pelo princípio da intervenção mínima na autonomia da vontade coletiva, será, portanto, possível verificar qual a natureza desse princípio, se de caráter normativo e vinculantes ou apenas servirá de diretriz e como será realizada a ponderação entre o princípio da intervenção mínima e o princípio da proteção?

O que se depreende desse princípio da intervenção mínima é uma aparente valorização da autonomia da vontade de contratar. Aparente porque se ela prevalecer em desfavor da parte vulnerável sem que haja possibilidade de rediscutir a matéria, isso acarretaria em negativa na prestação jurisdicional e, por conseguinte, falha ao acesso à justiça com direito fundamental.

\section{AUTONOMIA PRIVADA INDIVIDUAL E COLETIVA}

Cumpre conceituar autonomia privada que nas palavras de Cassettari 
(2013, p. 188) é o princípio que confere às partes liberdade de autorregulamentação, ou seja, permite que as partes possam convencionar o que melhor lhes aprouver.

Da análise quanto a diferenciação entre autonomia privada e autonomia da vontade extrai-se o fato do fenômeno de deslocamento de uma era de patrimonialização para um novo momento de personificação, aquele diz respeito a valorização do patrimônio em detrimento ao indivíduo, de maneira que superando esse conceito materialista, vive-se o período da valorização da pessoa humana (CASSETTARI, 2013, p. 188).

Nesse sentido, mantendo a correlação entre a esfera cível e trabalhista, vez que envolvem matérias correlatas, contrato, direitos da personalidade entre outros, a autonomia privada também assim lhes são comuns, isso na medida que ela é um dos princípios fundamentais do sistema do direito privado brasileiro que reconhece uma esfera privada de atuação com eficácia jurídica (MEIRELES, 2009, p. 73).

Contudo, embora essa valorização da pessoa humana, os contratos, como espécies de negócios jurídicos, que decorre do exercício da autonomia da vontade, estes são regulados e tutelados pelo ordenamento jurídico conforme exposto no tópico acima. De maneira que o Poder Legislativo, com base em suas prerrogativas, disciplina a forma pela qual as relações interpessoais devem ser regidas e constituídas, bem como o Poder Judiciário poderá intervir em casos de reequilíbrio contratual, declarar nulo o contrato entre outras modalidades de intervenção estatal para garantir a eficácia dos comandos normativos.

[...] a autonomia privada merece alguma reflexão para além da ligeira e consagrada opinião de tratar-se, ela, do princípio nuclear e fundamental de todo o Direito Privado. Necessário seguir à frente e descortinar a atual natureza jurídica e ideológica da autonomia privada, pois, como adiante será compreendido, o incorreto posicionamento deste princípio, no plano da sua legalidade constitucional, pode trazer imensos retrocessos ao sistema jurídico privado, sobretudo ao contratual. (NALIN, 2006, p. 20).

A Intervenção do Estado, seja pelo Poder Legislativo, ou Judiciário nas relações interpessoais, é, em última análise o comando normativo disciplinador daquele conteúdo que gerará maior ou menor liberdade de atuação às partes. Corrobora com essa tese as palavras de Meireles (2009, p.74): 


\begin{abstract}
Autonomia privada significa auto-regulamentação de interesses, patrimoniais e não patrimoniais. Trata-se de um princípio que confere juridicidade àquilo que for definido pelo titular para o regramento de seus interesses, por meio das vicissitudes jurídicas relacionadas às situações subjetivas respectivas. Importante ressaltar que esse autoregramento de interesses somente alça juridicidade porque assim reconhecido no mundo jurídico, não simplesmente porque emana da vontade.
\end{abstract}

Diante do exposto, assiste razão a autonomia privada em um Estado Democrático de Direito com ambiente juridicamente equilibrado e organizado de maneira a disciplinar as relações interpessoais concedendo-lhes liberdade e autonomia, sem, contudo, afastar-se da prerrogativa e dever de intervir nas relações sociais descompassadas das previsões legais.

Todavia, merece ater-se ao fato de que, por ser autonomia privada, cabe ainda esclarecer quem é o privado a que se refere. Dentro da esfera da autonomia privada pode-se encontrar atos de autonomia individual e coletiva. Os atos de autonomia individual são aqueles realizados pela pessoa, individualmente considerada, a exemplo do contato de compra e venda. Os atos de autonomia coletiva são aqueles resultantes da vontade de uma pluralidade, referentes ao poder do grupo organizado como instrumento, como formação social, para tornar possível a formação de todos na vida do país e favorecer o pleno desenvolvimento da pessoa, a exemplo do contrato coletivo de trabalho (MEIRELES, 2009, p. 77).

No âmbito do direito do trabalho a de se falar em o exercício da autonomia privada individual e autonomia privada coletiva, na medida que a primeira se refere aos contrato e efeitos produzidos na esfera de um indivíduo/empregado, por outro, na segunda hipótese está diante da negociação e formulação de contratos coletivos envolvendo uma categoria/classe de empregados com interesses e direitos comuns.

\title{
3.1 AUTONOMIA PRIVADA INDIVIDUAL - LABORAL
}

Após a construção breve da correlação entre a relação contratual disciplinada no Código Civil e Consolidação das Leis do Trabalho, conceituação do que se entende por autonomia privada, passasse a abordagem mais precisa 
na esfera laboral, vez que a pesquisa, nesse tópica, visa a análise quanto a Intervenção do Estado no que tange a autonomia da vontade coletiva, portanto, no que se refere a autonomia privada individual laboral apresentar-se-á a conceituação e aplicabilidade, deixar-se-á maior atenção a regulação coletiva da temática proposta neste artigo.

Para maior compreensão da autonomia privada individual na esfera trabalhista vale-se do artigo 444 da Consolidação das Leis do Trabalho, segue:

\begin{abstract}
Art. 444 - As relações contratuais de trabalho podem ser objeto de livre estipulação das partes interessadas em tudo quanto não contravenha às disposições de proteção ao trabalho, aos contratos coletivos que Ihes sejam aplicáveis e às decisões das autoridades competentes. Parágrafo único. A livre estipulação a que se refere o caput deste artigo aplica-se às hipóteses previstas no art. 611-A desta Consolidação, com a mesma eficácia legal e preponderância sobre os instrumentos coletivos, no caso de empregado portador de diploma de nível superior e que perceba salário mensal igual ou superior a duas vezes o limite máximo dos benefícios do Regime Geral de Previdência Social. (BRASIL, 2017a).
\end{abstract}

As relações laborais são, na maior parte dos casos, marcadas pelas desigualdades das partes, a vinculação é de hipossuficiência e subordinação econômica, de maneira que, nas palavras de Cassar (2009, p. 193), se justifica a Intervenção do Estado para que estabeleça condições mínimas de condições de trabalho, assim, o contrato de trabalho tem suas regras mínimas impostas por lei, uma vez que os contratantes não possuem igualdade econômica.

O direito do trabalho possui princípios próprios, a título de exemplo citase o Princípio da Proteção do Trabalhador, que nas palavras de Süssekind (1997, p. 152/153):

\begin{abstract}
Resulta das normas imperativas e, portanto, de ordem pública, que caracterizam a intervenção básica do Estado nas relações de trabalho, visando a opor obstáculos à autonomia da vontade. Essas regras cogentes formam a base do contato de trabalho - uma linha divisória entre a vontade do Estado, manifestada pelos poderes competentes, e a dos contratantes. Estes podem complementar ou suplementar o mínimo de proteção legal.
\end{abstract}

Ora, se de um lado existe o princípio da proteção do trabalhador e, concomitantemente há lei que disciplina a livre autonomia contratual do alto empregado sendo aquele com diploma de curso superior nos termos do artigo 444, parágrafo único da lei 13.467/17 (BRASIL, 2017a) é de supor não haver 
conflito entre princípio e norma, mas de coexistência e aplicação conjugada da lei com a diretriz principiológica, ou ainda, entender haver um conflito entre a norma e o princípio, e, por conseguinte, diante do caso concreto se valer dos métodos de interpretação e ponderação para resolução do litígio.

Contudo, há ressalvas apresentas por Cassar (2017, p. 47) que entende que a partir da Lei no. 13.467/2017 (BRASIL, 2017a), os empregados portadores de diploma de nível superior e que recebem salário igual ou superior a duas vezes o limite dos benefícios da Previdência Social poderão negociar com seus empregadores os direitos previstos no art.611-A da CLT, com prevalência desse negócio individual escrito sobre a lei. Poderá, ainda, renunciar os direitos previstos nas normas coletivas, pois o ajuste individual prevalecerá sobre a norma coletiva.

À luz principiológica da proteção do trabalhador, nos ditames acima, verifica- se que a legislação trabalhista nasce visando tutelar os direitos e obrigações oriundas da relação laboral, sobretudo, garantir ao empregado condições de dignidade, a propósito, assim se manifestou Maranhão (1997, p. 254):

O contrato de trabalho é um contrato regulamentado. Como esclarece La Cueva, tem o direito do trabalho como finalidade primeira proteger a saúde e a vida do trabalhador e garantir-Ihe um nível de vida compatível com a dignidade humana. E, se este é seu propósito, é natural que, estando condicionada à realização desse objetivo pelo conteúdo da relação de trabalho, tivesse a lei o cuidado de fixa-lo de modo imperativo. A lei contém um contrato mínimo de trabalho, para usarmos a expressão feliz de La Cuerva. E este contrato mínimo se impõe à vontade das partes na estipulação de cada contrato individual.

Assim, o princípio da proteção, bem como artigo 444 da CLT (BRASIL, 2017a) que estabelece que:

As relações contratuais de trabalho podem ser objeto de livre estipulação das partes interessadas em tudo quanto não contravenha às disposições de proteção ao trabalho, aos contratos coletivos que Ihes sejam aplicáveis e às decisões das autoridades competentes.

Isso equivale a dizer que a previsão legal, bem como a tutela jurisdicional do trabalho vem para proteger o empregado de ações que possam lhe causar 
prejuízos econômicos e, inclusive de subsistência, mas também de proteção contra si próprio de maneira que não há que se falar em autonomia privada individual quando desrespeitar e ferir condições contratuais mínimas.

A propósito, corrobora com essa afirmação Maranhão (1997, p. 254) ao dizer que a autonomia da vontade individual, portanto, embora limitada no que respeita às condições contratuais mínimas, resultantes da lei, do contrato coletivo ou da sentença normativa, subsiste no contrato de trabalho, seja, necessariamente, na formação do contrato, que é um acordo de vontade, seja na estipulação de seu conteúdo quando este for além do mínimo legal.

Diante do que até aqui exposto, a autonomia privada individual subsiste em um Estado Democrático de Direito também porque há a Intervenção do Estado que lhe garante condições contratuais mínimas condizentes com valores fundamentais do trabalho e dignidade da pessoa humana.

\title{
3.2 AUTONOMIA PRIVADA COLETIVA - LABORAL
}

Assim como a autonomia privada no âmbito cível encontra tutela constitucional, também ocorre na esfera do direito do trabalho vez que as relações lá e cá estabelecidas criam, modificam e extinguem obrigações mútuas com reflexos e efeitos no mundo jurídico. Particularmente em âmbito laboral, há tanto a autonomia privada individual e a autonomia privada coletiva a qual passase a ser analisada.

Nas palavras de Silva (2015, p. 157):

\begin{abstract}
Reside a negociação coletiva na essência do direito do trabalho. (...) Não fosse pelo poder da negociação coletiva, talvez o direito do trabalho ainda estivesse inserido em algum apêndice do direito civil, pois não passaria de um acervo sobre a relação jurídica que une trabalhador, empreendimento de sua energia e empregador. (...) E na negociação coletiva, surge o inusitado efeito de serem alcançadas pessoas estranhas às tratativas, inexistentes à época da elaboração da norma coletiva e, tanto mais assombroso, com a possibilidade de alteração de preceitos legais.
\end{abstract}

A conceituação do que vem a ser Convenção Coletiva encontra-se no artigo 611 da CLT, (BRASIL, 2017a): que em síntese define ser a Convenção Coletiva de Trabalho um acordo de caráter normativo, pelo qual dois ou mais Sindicatos representativos de categorias econômicas e profissionais estipulam 
condições de trabalho aplicáveis, no âmbito das respectivas representações, às relações individuais de trabalho.

Esse conceito, nas palavras de Silva (2015, p. 157/158), encaixa-se à perfeição no ideal trabalhista de solução rápida de conflitos e de fixação de patamares melhores para atender às peculiaridades de cada profissão, segmento e região geográfica.

Os sindicados representativos de determinada categoria profissional e econômica atuam em defesa dos direitos e interesses coletivos ou individuais em questões judiciais ou administrativas, assim disciplina o artigo 8, III, da Constituição de 1988. (BRASIL, 1988). À luz do dispositivo constitucional resta claro que a Intervenção do Estado se faz necessária na medida em que há interesses opostos nas relações laborais e, por conseguinte, geram efeitos no âmbito econômico das partes.

Assim o Estado para garantir a efetividade dos direitos sociais trabalhistas - conforme mencionado, para preservar o mínimo contratual, age em prol da classe presumivelmente vulnerável em determinada relação. A título de exemplo, assim o faz nas relações consumeristas onde presume-se ser o consumidor vulnerável, isso ocorre para que se efetive a transição da igualdade formal para a igualdade substancial.

Nas palavras de Meireles (2009, p. 82):

\begin{abstract}
Com a maior participação do Estado nas relações privadas, foi possível a passagem da igualdade formal para a igualdade substancial. Afinal, a igualdade contratual que servia de substrato para dar força obrigatória à vontade das partes não passa de um mito. A autonomia privada sob a lógica individualista era pautada pela igualdade formal, enquanto que a lógica do Estado Social impõe que seja reconhecida a desigualdade a fim de que com o tratamento diferenciado entre desiguais possa ser satisfeita substancialmente a igualdade. Exemplo disso se encontra no Código de Defesa do Consumidor que presume ser o consumidor vulnerável.
\end{abstract}

Veja-se, portanto, que a autonomia privada coletiva expressa no instrumento denominado Convenção Coletiva de Trabalho que se concretiza na negociação coletiva é o meio mais eficaz para a solução dos conflitos coletivos e, através dela, é que se encontram fórmulas para que seja mantida a paz social. (TEIXEIRA FILHO, 1997, p. 1072).

Conforme mencionado do capítulo anterior, tanto a autonomia privada 
individual como a coletiva, o seu exercício pleno depende, em última análise, da densidade do texto legal, ou seja, a lei concederá ou restringirá o conteúdo daquilo que poderá ser objeto de negociação coletiva de maneira, portanto, que quanto maior a restrição no que tange o conteúdo negociável, menor será a autonomia privada.

Corrobora com essa alegação as palavras de Teixeira Filho (1997, p. 1078):

O Estado e a negociação coletiva. É inquestionável que o espaço reservado à negociação coletiva é produto do maior ou menor grau de intervencionismo estatal na disciplina desse processo de entendimento, do protagonismo que os atores sociais têm no seu desenvolvimento e estruturação e, por fim, da frequência com que a lei antecipa o que deveria ser o conteúdo da negociação. (1997, p. 1078).

A Intervenção do Estado pode, portanto, ocorrer em dois momentos, na elaboração da lei (Poder Legislativo) que disciplinará a matéria naquilo que poderá ser objeto de negociação coletiva, bem como poderá e deverá intervir o Poder Judiciário quando provocado para equilibrar relações e resolver o litigio que se estabelece decorrente de uma pretensão resistida, que é, em última análise, quando nasce o direito de ação.

Diante dessas hipóteses de Intervenção do Estado é que a nova redação do art. 611-A da CLT, que em linhas gerais dispõe que - a convenção coletiva e o acordo coletivo de trabalho, observados os incisos III e VI do caput do art. 8 da Constituição, têm prevalência sobre a lei (...). (BRASIL, 2017a).

Assim, para que melhorem as condições de trabalho, Luiz Eduardo Gunther entende que a negociação coletiva apresenta a grande justificativa de poder ser rápida e eficiente, solucionando-se eventual conflito pelos próprios interlocutores sociais, os sindicatos a frente, como verdadeiros entes coletivos, para justificarem o equilíbrio relativamente ao poder empresarial.

Os artigos em análise trazidos pela Reforma Trabalhista, Lei no. 13.467/2017, (BRASIL, 2017a) revelam um descompasso entre o Poder Legislativo com o que se construiu com a atuação dos operadores do direito, advogados, Membros do Ministério Púbico do Trabalho, Juízes e as Cortes Superiores, enfim, o Poder Judiciário em âmbito trabalhista, isso porque busca corrigir distorções da má aplicação das leis ou inobservância delas com base, 
inclusive em princípios.

$\mathrm{Na}$ tentativa de mitigar as ações trabalhistas, o Poder Legislativo apresenta comandos normativos que esvaziam a amplitude de atuação do Poder Judiciário, sobretudo dos juízes trabalhistas, nos termos do $\S^{\circ}$ do art. $8^{\circ}$ da Lei №. 13.467/2017 (BRASIL, 2017a), prevendo o princípio da Intervenção Mínima, - que ocorre também com outros dispositivos alterados pela Reforma Trabalhista.

A título de exemplo, nas palavras de Araújo (2017, p. 230)

\begin{abstract}
O caput do artigo611-A da CLT apresenta equívoco ao não distinguir associados e não associados, medida que se fazia necessária por conta da extinção da contribuição sindical obrigatória. Além disso, ao incluir a expressão "entre outros" na sua redação, torna genérica e exemplificativa hipótese de flexibilização, quando deveria ser restritiva a possibilidade de supressão ou redução de direitos por norma coletiva.
\end{abstract}

A ideia de autonomia privada já vinha disciplinada na CLT em seu artigo 444 que dispõe que "as relações contratuais de trabalho podem ser objeto de livre estipulação das partes interessadas em tudo quanto não contravenha às disposições de proteção ao trabalho, aos contratos coletivos que Ihes sejam aplicáveis e às decisões das autoridades competentes". (BRASIL, 2017a).

Nesse dispositivo, embora refira-se a direitos individuais, a livre estipulação se estende às hipóteses do art. 611-A da CLT, de maneira que com o advento da Lei no. 13.467/2017 (BRASIL, 2017a) a autonomia privada ganha mais espaço de atuação, tanto nas relações individuais como nas coletivas.

Nesse sentido corrobora Lopes Filho (2017, p. 159) ao dizer que a reforma aqui comentada teve como principal objetivo dar autonomia às partes envolvidas na relação trabalhista, vez que nos debates no Congresso Nacional, durante a tramitação da reforma, julgou-se que um trabalhador com graduação em ensino superior e salário acima da média remuneratória da maioria da população não deveria ser tratado como alguém vulnerável, que necessite de proteção do Estado ou de tutela sindical para negociar seus direitos trabalhistas.

Evidenciada essa dicotomia entre a previsão legal e a aplicação pelo judiciário daquelas disposições legais, no que tange a autonomia privada, em nome da segurança jurídica, a Intervenção do Estado legislador vem para reverenciar a autonomia privada fazendo com que o Estado Juiz tenha atuação 
mitigada naquilo que seja objeto de negociação entre os sujeitos de direito envolvidos em determinada relação laboral.

Nesse sentido Teixeira Filho explica (1997, p. 1079):

As razões para isso são óbvias: é para que haja uma ampla e saudável descentralização capaz de dar respostas e soluções mais justas e mais racionais às demandas; para que se estimule o senso de responsabilidade e de participação de cada cidadão, que, assim, assumirá o papel de artífice de seu próprio destino e não ficará esperando as soluções padronizadas do Estado; e para evitar que os cidadãos tenham de enfrentar-se sempre diretamente com o próprio Estado, sem os amortecedores dos corpos mediadores.

Significa, portanto, a negociação coletiva, um instrumento que valoriza a capacidade de exercício de responsabilidades no que tange as escolhas feitas ao estipularem condições, termos e encargos no ato de pactuarem e aproximarem interesses. Assim, Teixeira Filho complementa (1997, p. 1079):

E a negociação coletiva constitui o processo mais adequado para se estruturar uma verdadeira rede de regras privadas, revistas e aprimoradas a cada exercício da autonomia coletiva, sempre objetivando reduzir a folga, o espaço faltante entre o trabalho e 0 capital, distância essa que nem mesmo a mera intervenção legislativa se mostrou capaz de corrigir. Isso não significa menosprezar a função reguladora que o Estado efetivamente tem a desemprenhar. Significa, isto sim, reconhecer a existência de uma vertente autônoma voltada para a busca - cada vez mais ostensiva e mais autêntica da realização da justiça social.

Diante do exposto, a autonomia privada coletiva, assim como a individual, renasce com a promulgação da Lei no. 13.467/2017 (BRASIL, 2017a) a fim de, em tese, aproximar os sujeitos de direito envolvidos na relação trabalhista para que seus interesses sejam negociados sem a intervenção do próprio Estado, bem como celeridade aos conflitos oriundos da relação laboral.

Ocorre que nas relações oriundas dos negócios jurídicos, em que se respeitou o plano da existência, validade e eficácia, e, ainda, privilegiou a autonomia privada, seja a individual ou coletiva, esse cenário se dá em um ambiente de relações contratuais, ou seja, onde há interesses econômicos, seja daquele que detém os meios de produção, ou daqueles que se valem da força física e/ou capacidade intelectual para auferirem renda para subsistência.

Assim, é nesse espaço econômico, denominado de mercado, que contratos são firmados, direitos, obrigações e deveres nascem e se extinguem 
pela via da prestação jurisdicional, é nesse contexto que se depara com necessidades essenciais, pretensões resistidas, vulnerabilidade dos agentes econômicos, instabilidade nas negociações e relações jurídicas frustradas, que se faz necessária a presença do Poder Judiciário a fim de prestar a tutela aos jurisdicionados. De igual modo, é no mesmo cenário que o Poder Legislativo enfrenta tais questões a fim de mitigar os efeitos nocivos à sociedade.

A questão reside quando o fenômeno econômico sobressai sobre 0 jurídico, quando interesses econômicos ganham espaço nas decisões legislativas a ponto do jurídico, restar-se a se conformar com as imposições do mercado e/ou interesse de classes dominantes.

A liberdade econômica outorga aos agentes a autonomia privada, portanto, inegável a importância desse modelo de Estado que privilegia o princípio da liberdade, entretanto, a outra face deste mesmo modelo de Estado, direciona-se ao social, prestigiando, por sua vez, o princípio da solidariedade, exemplo disso é a função social do contrato, assim, conciliar interesse coletivo e individual torna-se um desafio. E nesse viés, há estreita convivência entre a ciência econômica e a ciência do direito.

Nessa perspectiva, Barbosa (2014, p. 633), levanta a indagação, "qual a relação que se estabelece entre àquela e o direito". A questão exposta pela portuguesa, vincula-se à pesquisa no tocante à autonomia privada individual ou coletiva em um cenário de preponderância econômica, ainda mais quando esta é capaz de influenciar na elaboração da norma jurídica.

Barbosa ainda enfatiza que (2014, p. 636):

\footnotetext{
Reconhecemos, sob pena de padecermos de autismo obnubilador da realidade, que a dimensão económica não pode deixar de influenciar a juridicidade, mas não nos esquecemos que esta tem uma intencionalidade própria que não se pode deixar condicionar pela estrutura da economia.
}

Esse entrechoque entre interesse econômico e estrutura jurídica, sobretudo, tutela jurisdicional, se verifica quando, em nome de um instituto jurídico, visa-se impor regras de direito de cunho econômico. Em outras palavras, em nome da segurança jurídica e maior espaço para negociação, ou seja, autonomia privada (individual ou coletiva), incentivar a elaboração da norma jurídica com nítido viés e reflexo econômico aos destinatários da norma, inclusive 
visando a impossibilidade de intervenção por parte da Justiça Trabalhista, o que se verifica com a inserção do parágrafo terceiro no artigo oitavo.

A propósito, vale-se das palavras de Barbosa (2014, p. 638):

\begin{abstract}
As leis são hoje instrumentos de prossecução de determinada política de governo do Estado. Nessa medida, elas necessariamente reflectem dados economicamente cunhados e procuram, por si mesma, prosseguir determinados objetivos eficientistas. Contudo, isto não nos pode conduzir à assunção de que as normas têm incontornavelmente um conteúdo economicamente densificado e que, por isso, todo o ordenamento jurídico reflecte uma escolha valorativa assente em pilares tecnocráticos.
\end{abstract}

Isso é o que se viu, por exemplo, na política de desoneração da folha de pagamento no governo Dilma e, posteriormente, na proposta de veto a essa lei pelo governo Temer. Em ambos os casos, a motivação era econômica. Se prevalecer a pretensão econômica sobre o direito, consequentemente, o acesso à justiça tender- se-á a ser cada vez mais limitado, vez que para tanto, há custos, o que por si só já mitiga o exercício do direito constitucional de busca da prestação jurisdicional do Estado.

Ocorre com certa frequência, se valer da via legislativa para tentar resolver questões econômicas, dentre outras, a propósito, Vaz (1989, p. 83), esclarece:

Por um lado, o problema econômico é anterior ao direito, no sentido de que este deve servir a realidade de que a economia é um dos aspectos. Assim, o direito fornece quadros mentais de enquadramento da realidade econômica e assegura, através dos seus institutos e mecanismos, a salvaguarda de posições adquiridas ou a adquirir. Mas, por outro lado, seria erro considerar o direito (como servo da economia): a regra jurídica exprime, na verdade, certas exigências às quais a economia tem de submeter-se.

Persiste, ao que se observa, a dúvida quanto à vinculação entre Direito e Economia, contudo, revela-se que as garantias constitucionais devem ser vistas e interpretadas de forma impositiva e que em relação a elas, interesses que não corroborem para a sua efetivação, devem ser rechaçadas, o que inclui pretensão normativa de cunho econômico tendenciosa a suprimir conquistados e assegurados na Constituição de 1988, sobretudo, os direitos sociais, nesse particular, trabalhistas.

Relembre-se que a estrutura normativa, bem como a metodologia 
estruturante do Direito permite valer-se de outras fontes para normatividade jurídica, o que significa dizer, que o Poder Legislativo e/ou Executivo, não são os detentores absolutos de impor regras de condutas, podendo, por conseguinte, o ordenamento jurídico ser composto de princípios e, de reiteradas decisões em mesmo sentido. Ou seja, o direito não se limita à lei.

A propósito, Barbosa (2014, p. 638), esclarece:

\begin{abstract}
Estamos longe do reducionismo que identificava a lei com o direito. Ora, isso significa não só que existem mais fontes da normatividade jurídica vigente para além das normas, como que estas têm de encontrar a sua legitimidade em algo que vá para além da forma do poder politicamente legitimado para as produzir.
\end{abstract}

Nesse sentido, a autonomia privada - individual ou coletiva - que se legitima no princípio da liberdade, não pode ser utilizado como subterfúgio para simular uma aparente maior liberdade e autonomia para negociar, tampouco pode esse princípio sobressair em detrimento ao princípio da justiça social ou princípio protetivo, deve-se, portanto, harmonizar a liberdade com a solidariedade.

\title{
4. O PRINCÍPIO DA INTERVENÇÃO MÍNIMA VIOLA O PRINCÍPIO DO ACESSO À JUSTIÇA EM CASO DE CONSTATAÇÃO DE HETERONOMIA DA VONTADE?
}

Talvez seja essa a questão central e mais difícil da pesquisa, mas gerar a curiosidade sobre o tema e chamar a atenção para o que dele pode derivar, a fim de analisar seu potencial em restrição ao acesso à justiça com a inserção desse novo princípio ao Direito do Trabalho. Uma questão a considerar para tentar responde essa questão é: Esse princípio da intervenção mínima é justo?

A este respeito, Sandel (2017, p. 138) explicita "o simples fato de a maioria, por maior que seja, concordar com uma determinada lei, ainda que com convicção, não faz com que ela seja uma lei justa".

Ocorre que essa pretensão em homenagear a autonomia da vontade, a qual se verifica com a redação do caput art. 611-A, CLT, liga-se mais a uma ideia de heteronomia da vontade do que a própria autonomia. Esse conceito de 
heteronomia decorre do entendimento de Kant ao "dizer quando fala em agir com autonomia é comparar o conceito de autonomia com o seu oposto". (SANDEL, 2017, p. 141).

O que significa essa expressão inventada por Kant para indicar oposição à palavra autonomia, é "quando ajo com heteronomia, ajo de acordo com determinações exteriores". (SANDEL, 2017, p. 141). Isso tem a ver com o conteúdo deste livro, na medida em que ao se tratar do princípio da intervenção mínima, é, por conseguinte, tratar da negociação coletiva e a possibilidade de interferência da Justiça do Trabalho nas relações laborais, o que indica também a autonomia da vontade privada coletiva. Isso é a prevalência do negociado sobre o legislado.

Contudo, pela perspectiva kantiana, o que se depreende da análise de alguns dispositivos da Reforma Trabalhista não é a valorização da autonomia da vontade privada coletiva, mas de uma heteronomia da vontade, onde constatase estar viciada a vontade expressa na CCT ou ACT, isso porque pactuado por influências e determinações externas, seja a inexperiência e/ou necessidade de subsistência.

Importante deixar claro, e muito esclarecido, que se concorda com a possibilidade de os interessados negociarem seus termos nas negociações coletivas. Concorda-se, também, a importância que há nelas, assim como mencionado neste trabalho. Entretanto, nos termos expostos na Lei no. 13.467/2017, a cautela na análise dos dispositivos que tratam da negociação coletiva e princípio da intervenção mínima, fazem imprescindíveis para traçar um prospecto de seus possíveis efeitos e consequências.

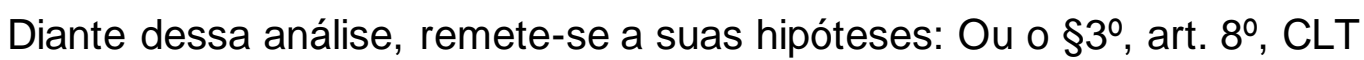
é inconstitucional porque viola o princípio do acesso à justiça, ou caso se verifique, havendo desproporcionalidade no CCT ou ACT, essa negociação coletiva poder-se-á ser anulada com base no art. 157, CC/02. Em outras palavras, há vício nesse negócio jurídico porque se percebe a heteronomia da vontade e não autonomia.

Portanto, autonomia para escolher vincula-se à liberdade de poder decidir desvencilhado de elementos externos que viciem a capacidade de sua autonomia, em outras palavras, e valendo-se das palavras de Sandel (2017, p. 141/142) "agir livremente não é escolher as melhores formas para atingir 
determinado fim; é escolher o fim em si - uma escolha que os seres humanos podem fazer (...)".

Para entender como se encaixa a expressão "heteronomia", usa-se a justificativa apresentada pela CNI (2012) para as propostas de modernização trabalhista:

\begin{abstract}
É amplamente reconhecido que o sistema trabalhista do país não atende às necessidades da sociedade brasileira contemporânea. Calcada em um regime legalista rígido e com pouco espaço para negociação, e regulação tem escassa conexão com a realidade produtiva. (...) Pretende-se, com este trabalho, preservar a discussão sobre a proteção e os direitos dos trabalhadores, agregando ao debate item como custo, produtividade e segurança jurídica. Isso é fundamental para que o país avance em direção a uma regulação mais adequada do tema.
\end{abstract}

A CNI apresenta uma problemática para justificar a alteração legislativa trabalhista, partindo de uma premissa equivocada no que tange a suposta rigidez da legislação. Isso porque há possibilidade de negociação coletiva, razão pela qual, a suposta inflexibilidade da norma trabalhista, não é razão de modificá-la sob este argumento.

Ao final do trecho destacado como exemplo, a CNI justifica sua pretensão com a seguinte frase: "Isso é fundamental para que o país avance em direção a uma regulação mais adequada do tema". Em síntese, o que significa é que a alteração legislativa, mesmo que diga respeito à direitos sociais, dignidade do trabalhador, são instrumentos de meio para atingir a finalidade de avanço do país.

Nas palavras de Sandel (2017, p. 142):

\begin{abstract}
Esse é um exemplo daquilo que Kant chamaria de determinação heteronômica - fazer alguma cosia por causa de outra coisa, por causa de outra coisa, e assim por diante. Quando agimos de maneira heteronômica, agimos em função de finalidades externas. Nós somos os instrumentos e não os autores, dos objetivos que tentamos alcançar.
\end{abstract}

A justificativa da alteração legislativa trabalhista vincula-se a uma finalidade que não é o trabalhador, mas o desenvolvimento econômico do país, o que é uma justificativa válida se a finalidade da CLT não fosse primordialmente tutelar as relações de trabalho e, sobretudo, trabalhador.

A propósito, Sandel (2017, p. 143) "para Kant, o respeito à dignidade 
humana exige que tratemos as pessoas como fins em si mesmas". Entretanto, a justificativa da Reforma Trabalhista deixa de ser o indivíduo a finalidade para ser meio a um determinado fim, o econômico.

Esse desenvolvimento argumentativo, se fez necessário para construir a resposta à pergunta quanto ao princípio da intervenção mínima se "Esse princípio é justo?". Diante do exposto, se a conclusão extraída, desde a perspectiva filosófica até o que foi analisado anteriormente, for que o princípio da intervenção mínima é justo, ter-se-á uma nova fase da lei, onde a sua finalidade não será mais o social, mas o econômico, e para isso, se preciso for usar os indivíduos como meio para alcançar a finalidade, normativamente será justificável.

Por outro, se os argumentos apresentados, indicam para uma injustiça, logo, a tendência é de ser também inconstitucional, vez que contrária a finalidade da lei, (LINDB), bem como oposto aos objetivos do art. $3^{\circ}$ da Constituição Federal de 1988, em especial, os incisos: I - construir uma sociedade livre, justa e solidária; II - garantir o desenvolvimento nacional; III - erradicar a pobreza e a marginalização e reduzir as desigualdades sociais e regionais. Assim, como opõem-se aos seus fundamentos, em particular, os incisos III - a dignidade da pessoa humana e, IV - os valores sociais do trabalho e da livre iniciativa. Por fim, fere $\mathrm{o}$ art. $7^{\circ}$, que trata da tutela dos direitos trabalhistas.

\section{CONCLUSÃO}

Constatou-se que a autonomia privada coletiva que a Reforma Trabalhista trouxe, numa perspectiva kantiana, se aproxima mais da heteronomia da vontade, vez que manifestadas com pressão externas, seja a inexperiência ou necessidade.

\section{REFERÊNCIAS}

BRASIL. Constituição da República Federativa do Brasil de 1988. Disponível em: <http://www.planalto.gov.br/ccivil_03/constituicao/constituicaocompilado.htm>. 
Acesso em: 15 nov. 2017.

.Lei no 13.467, de 13 de julho de 2017. (Lei da Reforma trabalhista)

Disponível em: <http://www.planalto.gov.br/ccivil_03/_ato2015-

2018/2017/lei/L13467.htm>. Acesso em 5 de dez. 2017.

Lei no 10.406, de 10 de Janeiro de 2002. Disponível em: < http://www.planalto.gov.br/ccivil_03/leis/2002/L10406.htm>. Acesso em 5 de dez. 2017.

. Medida Provisória oㅡ 881, de 30 de abril de 2019. Diário Oficial da União, Brasília, DF, Edição extra. 14.04.2019.

CASSETTARI, Christiano. Elementos de Direito Civil. São Paulo, $2^{\underline{a}}$ ed. Saraiva, 2013.

GUNTHER, Luiz Eduardo. A negociação coletiva do trabalho como direito fundamental: necessidade de afirmação da tutela dos direitos de personalidade na atividade empresarial mundializada. Revista Jurídica UNICURITIBA, v. 21, n. 5, p.1-27 2008. Disponível em:

http://revista.unicuritiba.edu.br/index.php/RevJur/article/view/118.

Acesso em 13 de dez.de2017.

; VILLATORE, Marco Antônio César. Negociações coletivas de trabalho: As decisões judiciais e o princípio da fraternidade. Curitiba: Juruá, 2018.

KANT, Immanuel. Fundamentação da Metafísica dos Costumes. Tradução de Paulo Quintela - Lisboa: Edições 70, 2007

MARTINS, Ives Gandra da Silva. A constituição brasileira de 1988: interpretações. Rio de Janeiro, Forense Universitária, 1990.

MEIRELES, Rose Melo Vencelau. Autonomia privada e dignidade humana. Rio de Janeiro, Renovar, 2009.

MIRANDA, Pontes de. Democracia, liberdade, igualdade: os três caminhos. Campinas: Bookseller, 2002.

SANDEL, Michael. Justiça. O que é fazer a coisa certa. Tradução de Heloísa Matias e Maria Alice Máximo. 24.ed. Rio de Janeiro, Civilização brasileira, 2017.

SÜSSEKIND, Arnaldo; MARANHÃO, Délio; VIANNA, Segadas; TEIXEIRA, Lima. Instituições de Direito do Trabalho. 17. ed. São Paulo: LTr, 1997. v. 1. . Instituições de Direito do Trabalho. 18 ed. São Paulo: LTr, 1999, v. 2 VAZ, Manuel Afonso. A Problemática de um Direito Econômico. Coimbra, 1989. 